\title{
ERRATUM
}

\section{Telescopes and Interferometers}

T. Andersen and A. Enmark, Integrated Modeling of Telescopes,

Astrophysics and Space Science Library 377, DOI 10.1007/978-1-4614-0149-0,

(C) Springer Science+Business Media, LLC 2011

\section{DOI 10 1007/978-1-4614-0149-0_13}

The publisher regrets the error published in chapter 5, page 99, in the print and online versions of this book. The correct equations for 5.11 and 5.12 are given below.

$$
\begin{gathered}
k_{1}=-1+\frac{2\left(f_{1}^{\prime}-b\right)}{m^{2}\left(f^{\prime}-b\right)}, \\
k_{2}=-\left(\frac{m-1}{m+1}\right)^{2}-\frac{2 f^{\prime}(m-1)}{(m+1)^{3}\left(f^{\prime}-b\right)} .
\end{gathered}
$$

The online version of the updated chapter can be found at http://dx.doi.org/10.1007/978-1-4614-0149-0_5 